\title{
Nanotechnology: A Tool for Improved Performance on Electrochemical Screen-Printed (Bio)Sensors
}

\author{
Elena Jubete, Oscar A. Loaiza, Estibalitz Ochoteco, Jose A. Pomposo, \\ Hans Grande, and Javier Rodríguez
}

New Materials Department, Sensors and Photonics Unit, Centre for Electrochemical Technologies (CIDETEC), Paseo Miramón 196,
20009 Donostia-San Sebastián, Spain

Correspondence should be addressed to Elena Jubete, ejubete@cidetec.es

Received 23 December 2008; Accepted 26 March 2009

Recommended by Wojtek Wlodarski

\begin{abstract}
Screen-printing technology is a low-cost process, widely used in electronics production, especially in the fabrication of disposable electrodes for (bio)sensor applications. The pastes used for deposition of the successive layers are based on a polymeric binder with metallic dispersions or graphite, and can also contain functional materials such as cofactors, stabilizers and mediators. More recently metal nanoparticles, nanowires and carbon nanotubes have also been included either in these pastes or as a later stage on the working electrode. This review will summarize the use of nanomaterials to improve the electrochemical sensing capability of screen-printed sensors. It will cover mainly disposable sensors and biosensors for biomedical interest and toxicity monitoring, compiling recent examples where several types of metallic and carbon-based nanostructures are responsible for enhancing the performance of these devices.
\end{abstract}

Copyright () 2009 Elena Jubete et al. This is an open access article distributed under the Creative Commons Attribution License, which permits unrestricted use, distribution, and reproduction in any medium, provided the original work is properly cited.

\section{Introducing Screen Printing Technology and the Applications of Nanomaterials in Screen Printed Electrodes (SPEs)}

Screen printing technology is a low-cost thick film process that has been widely used in artistic applications and more recently in the production of electronic circuits and sensors. In the $80 \mathrm{~s}$ the process was adapted to the production of amperometric biosensors [1-4], making their commercialization much easier. This was due to the multiple advantages that the technology offers including reduced expense, flexibility, process automation, reproducibility and wide selection of materials. A huge number of successful electrochemical devices have been built using this technique [5].

The process of screen printing is rapid and simple; it consists of squeezing an ink or paste through a patterned screen onto a substrate held on the reverse of the screen. Successive layers can be deposited by this procedure and repeat patterns can be designed onto the same screen to enhance production speed. The substrate needs to be an inert material, most commonly PVC [6], polycarbonate [7], polyester [8], or ceramic [9], although nitrocellulose [10] and glass fibre [11] are also employed. Each layer is deposited through the corresponding mask providing a specific pattern. These masks are prepared by a photolithographic technique with photosensitive gels and nylon, polyester or, stainless steel meshes.

There are mainly two types of pastes that can be used in screen printed electrode (SPE) production: conductive or dielectric inks. The conductive inks give rise to the formation of conductive tracks on the electrodes. They are based on an organic binder where gold, silver, platinum or, graphite are dispersed at high loads as conducting fillers. Recently water-based inks have also been employed [12-15]. Functional materials can also be part of the formulation such as cofactors, stabilizers and mediators, and more recently nanosized metals and carbon nanotubes. Dielectric inks are often based on polymers or ceramics and form the encapsulating layer of the sensor, delimiting the working area and electric contacts.

Regarding biosensors production via screen printing, the biological component (e.g., enzyme, antibody, nucleic acid) can be added in different ways, giving rise to different 
preparation alternatives; the deposition by hand or the electrochemical entrapment after a multilayer deposition process is the most used alternatives. Another possibility is to introduce the biological material in a printing paste, printing it as a last layer on the electrode surface or as a one step deposition layer forming a biocomposite with the rest of the ingredients [16]. However, the incorporation of the biomolecules in screen printing pastes depends on their nature and is not always possible due to the paste drying conditions that can often bring the denaturalization of the biocomponent. Some of the most commonly used configurations for screen-printing enzymatic biosensors were reviewed by Albareda-Sirvent et al. [17]. More recently, arrays have been developed with multiple working electrodes on the same printed strip, for simultaneous electrochemical detection of different analytes including phenol/pesticides [18-20] or several target sequences of hybridization in genosensors, with up to 8 working electrodes on the same strip [21].

The design of new nanoscale materials has found a wide range of applications in the field of sensors, revolutionizing this field. They have also started to find their place in screen printed devices, bringing uncountable benefits. Among them, carbon nanotubes, nanowires and metallic nanoparticles have lately become favorite tools in the sensor area, since they can promote the electron transfer reactions of many molecules, lower the working potential of the sensor, increase the reaction rate, improve the sensibility, or in case of biosensors, contribute to a longer stability of the biocomponent. In genosensors and aptasensors the metallic nanoparticles can serve also as electroactive labels for electrochemical stripping techniques (e.g., stripping voltammetry, stripping potentiometric detection). Nanowires have also received considerable attention in nanoscale electronics and sensing devices [22-26], due to their high aspect ratios, capability of multisegmented synthesis, and surface modification compatibility. Recent research supports that nanowires can be applied in biofuelcells [27], adaptive sensors [28], and enzymes-based electrochemical sensors [29, 30]. They are also interesting tools for magnetic control of electrochemical reactivity or to adapt on demand (bio)electrocatalytic transformations as it was shown for ethanol/methanol [29] and glucose detection $[27,31]$.

The incorporation of nanomaterials in SPEs can be done following different alternative strategies. In most of the cases the addition of nanoparticles or nanotubes into screen printed inks, although possible [32], is not an easy task. In spite of not suffering from temperature stability problems in the same extent as enzymes or nucleic acids, they are insoluble in many solvents that constitute the matrix of screen printing pastes. For these reasons, other methods have been developed that are applied after the printing. These postprinting modifications include drop casting of the working electrode with nanotubes dispersed in DMF/water [33], Nafion [34], polyethylenimine [35], or DMSO [36], or electrodeposition of metallic particles [37]. More examples will be discussed in the following sections.

There are many good reviews concerning the preparation and application of nanomaterials in electrochemical sensors
[38-50]. However, there are scarce references on them to screen printed devices as electrodic material to support these nanomaterials. On the other hand, there are articles reviewing advances in SPE sensors [16, 51-57], but their content on applications of nanomaterials into these types of sensors is limited. In any case, there is no review, to the best of the authors' knowledge, dedicated exclusively to the application of nanotechnology to screen printed sensors. The following sections will be addressed to meet this need, covering examples of practical applications of screen printed sensors in the clinical and environmental field, explaining their basic principles and recent improvements with the use of nanotechnology.

\section{SPE in Clinical Diagnosis}

2.1. Glucose. Due to the prevalence of diabetes in the developed nations, $85 \%$ of the current market of biosensors is aimed to glucose monitoring, resulting in more than $\$ 5$ billion expense [58]. Disposable screen-printed biosensors are widely employed to address this need of frequent glucose monitoring in diabetics, and they are also used in food industry for quality control. They show a superior performance compared to reflectance devices since they give a rapid and accurate answer using disposable strips with no risk of instrument contamination. This shift toward electrochemical sensing has already been accounted for companies like Roche Diagnostics, Lifescan, Abott, and Bayer giving rise to more than 40 blood glucose meters on the market.

The majority of these devices are based on screen-printed carbon electrodes modified with the enzyme glucose oxidase (GOX), which oxidizes glucose to gluconic acid. In these systems, the presence of a mediator is needed to achieve direct electron exchange between the electrode and the redox centers of GOX, since these centers are situated in the interior of an insulating glucoprotein shell which prevents the direct process [59]. There are two major types of mediators: hydrogen peroxide oxidation mediating reagents and enzymatic glucose oxidation mediating reagents. The first type is employed in sensors where the oxygen participates actively in the oxidation of glucose catalyzed by glucose oxidase forming gluconic acid and $\mathrm{H}_{2} \mathrm{O}_{2}$. Reduction or oxidation of $\mathrm{H}_{2} \mathrm{O}_{2}$ occurs at high potential in nonmediated electrodes. Therefore, mediators are employed in this type of glucose biosensors to lower such potentials. This is the case of prusian blue (PB) [60-64]). Instead of these mediators, metallized carbon can also be used in the working electrode as the dispersed metal particles have shown favorable catalytic activity to oxidation and reduction of $\mathrm{H}_{2} \mathrm{O}_{2}$. The second type of mediators, the artificial mediating reagents, offers the advantage of not requiring oxygen in the system, which is the limiting reagent in the first type of systems and thereby lowering their sensitivities.

The use of nanotechnology has served to improve both types of systems. As mentioned previously, dispersed metal particles can be used to diminish the oxidation potential of $\mathrm{H}_{2} \mathrm{O}_{2}$ in glucose sensing without the need of mediators. If these particles are in the "nano" range, cannot only the potential be decreased but also the sensitivity enhanced. Shen 
et al. [32] reached this effect very recently by adding iridium nanoparticles on a screen-printable homemade carbon ink based on hydroxyethyl cellulose, polyethylenimine and a commercial carbon material. They first made a study of feasibility applying this ink on the working electrode of a 3electrode configuration. Over the printed working electrode the enzyme (GOX) was covalently attached via glutaraldehide. They passed subsequently to successful mini disposable electrodes with a 3 -electrode configuration, with a working diameter of $1 \mathrm{~mm}$. These minielectrodes responded linearly to glucose between 0 to $15 \mathrm{mM}$ and needed as little as $2 \mu \mathrm{L}$ Sample volume.

Zuo et al. [65] used a silver nanoparticles-doped silica sol-gel and polyvinyl alcohol hybrid film on a PB-modified screen-printed electrode to immobilize GOX. Although they did not avoid the use of the mediator for $\mathrm{H}_{2} \mathrm{O}_{2}$ detection (PB), they doubled the sensitivity of the sensor comparing with the biosensor without nanoparticles. The immobilized GOX remained with a $91 \%$ activity for 30 days in buffer.

The synthesis, characterization and immobilization of $\mathrm{PB}$ nanoparticles of $5 \mathrm{~nm}$ diameter have been reported [66] as mediators in Indium Tin Oxide (ITO) electrodes for the amperometric detection of $\mathrm{H}_{2} \mathrm{O}_{2}$. A similar strategy could be applied to SPE for the $\mathrm{H}_{2} \mathrm{O}_{2}$-based glucose detection.

Some other examples of nanomaterials for glucose sensing are applied to biosensors that do not require the formation of $\mathrm{H}_{2} \mathrm{O}_{2}$. Guan et al. [67] dispersed multiwalled carbon nanotubes (MWCNTs) within mineral oil following the procedure described by Rubianes and Rivas [68]. They mixed the MWCNT dispersion with an enzymatic solution of glucose GOX in citrate buffer and potassium ferrocianide and deposited a drop of the mix over the working electrode of screen-printed electrodes. After the drop dried they tested these electrodes (several types varying the mixing time for enzyme/MWCNT) and compared them with the corresponding type without MWCNT. It was shown that the best response toward glucose was obtained in the systems where the MWCNTs were present and had been mixed with the enzymatic solution during 30 minutes before deposition. Longer mixing time would lead to axial electron transfer. A wider linear response range and higher sensitivity was reached when the MWCNTs were present.

$\mathrm{Lu}$ and Chen [69] drop-coated also the working electrode of their screen-printed strips with a solution containing magnetite nanoparticles $\left(\mathrm{Fe}_{3} \mathrm{O}_{4}\right)$ with ferricyanide. In this case, the enzyme (GOX) was added in a later stage, after the nanoparticle-containing drop had dried. Sensitivity of $1.74 \mu \mathrm{A} \mathrm{mM}^{-1}$ was achieved. Rossi et al. [70] prepared and functionalized $\mathrm{Fe}_{3} \mathrm{O}_{4}$ nanoparticles with amino groups to link them covalently with GOX. The GOX-coated magnetite maintained the enzymatic activity for up to 3 months. Although they could have applied this modified enzyme in screen-printed sensors, they opted for quantifying the oxygen consumption from the transformation of glucose to gluconic acid catalyzed by this enzyme by measuring the increase of the steady state fluorescence intensity of $\mathrm{Ru}(\text { phen })_{3}$. This consumption of oxygen increased with the glucose concentration so glucose was able to be monitored without any surface of sensing material but directly in the solution. In spite of being an elegant approach, a digital fluorescence imaging system was required, which is a more sophisticated piece of equipment than a small portable potentiostat.

Gao et al. [71, 72] built and patented a nanocomposite membrane to be screen printed into a carbon strip using an aqueous slurry ink of a diffusional polymeric mediator (polyvinyl ferrocene coacrylamide) on a PVPAC binder and alumina nanoparticles. The nanoparticulate membrane served not only as biosensing media but also for analyte regulating functions.

Wang et al. [27] reported the possibility of modulating the electrochemical reactivity toward glucose and methanol of a screen-printed working electrode using nickel nanowires. A screen-printed carbon strip served as the working electrode and was limited by a glass cylinder to form an electrochemical cell. $\mathrm{An} \mathrm{Ag} / \mathrm{AgCl}$ and platinum wire were used as reference and counter electrodes, respectively. The nanowires were previously grown by electrodeposition into nanopores of alumina membranes, then removed from the templates, washed and stored in a $\mathrm{KOH}$ solution until their use. After being magnetically separated from the storing solution, they were dispersed in a $\mathrm{NaOH}$ solution used as electrolyte and placed in the homemade electrochemical cell. The modulation of the magnetic field was performed by placing a small magnet under the working electrode surface. The magnetic properties of nickel and its catalytical action toward aliphatic alcohols and carbohydrates entitled this action, and an enhancement of the electrochemical signal was observed when the nickel nanowires were vertically oriented with a magnetic field. Similarly, when the nanowires were magnetically orientated in a horizontal position the enhancement was produced to a lesser extent. Moreover, such modulated redox transformation was observed multiple times, upon repetitive changes of surface orientation.

2.2. Cholesterol. The alarming increase of clinical disorders such as hypertension, heart related illnesses, cerebral thrombosis, arteriosclerosis, and coronary artery disease. due to abnormal levels of cholesterol in blood have stimulated the development of biosensors with the purpose of quantifying the levels of this compound. Besides, the quality control and nutritional labelling of foods in the food stuff industry is another application for the measurement of cholesterol $[73,74]$.

The biosensing element most commonly used in cholesterol biosensors is cholesterol oxidase (ChOx), which can be immobilized in the working electrode of screen-printed sensor, catalyzing the conversion of cholesterol in presence of oxygen and water into 4 cholestene- 3 one and hydrogen peroxide. As in the case of glucose biosensing, amperometric measurements of hydrogen peroxide are often monitored, and here the high potential also causes interferential problems (ascorbic acid, uric acid and other easily oxidizable species); so mediators are also required. Some commonly used mediators in cholesterol sensing are cobalt phtalocianine [75], ferrocene derivatives [76] and phenothiazine derivatives [77]. Another possibility is also to add a mediator for cathodic determination of $\mathrm{H}_{2} \mathrm{O}_{2}$ such as prusian blue 
(PB) [78], titanium dioxide [79] or metal hexacyanoferrate [80]. As in glucose sensing, there is also a possibility to avoid the route of $\mathrm{H}_{2} \mathrm{O}_{2}$ production; in this case peroxidase (POD) can be combined with $\mathrm{ChOx}$ with potassium ferrocyanide. The drawback of this last route can be that the air oxidation of ferrocyanide is taking place as a competitive reaction of the enzymatic oxidation since it can affect the system.

Several matrices have been employed to construct cholesterol sensors including glassy carbon or gold electrodes, graphite-Teflon, tungsten wire, ITO-coated glass and porous silicon. Advances implemented on these electrodes for cholesterol detection have been recently reviewed for Arya et al. [81], including the application of nanomaterials. However, there are only a few reports that focus on the development of disposable cholesterol biosensor. For example, in Arya's review only three out of one hundred cited references were based on screen-printed electrodes, two of them containing nanoparticles. This is an example of how the application of nanomaterials on screen-printed cholesterol sensors is a field that is yet starting.

A collaboration between Italian and Russian scientists has led to applications of gold nanoparticles [82] and very recently MWCNT [83] on screen-printed rhodium graphite electrodes for cholesterol detection. In both cases they did not use ChOx but opted for another enzyme, cytochrome P450scc, for its specific catalysis of cholesterol side chain. An interesting review on applications of this enzymatic family in biosensors can be found [84].

The same scientists had previously built a cholesterol sensor with this enzyme in SPE but without nanoparticles, by immobilisation of cytochrome P450scc biomolecule with glutaldehide or agarose hydrogels over the rhodium-graphite working area [85]. This sensor needed the use of a mediator for electronic transfer: riboflavin. By drop coating the working area with gold nanoparticles suspended in chloroform, they converted the electrode into a nonmediated system, since the roughness of the surface was enough to penetrate the protein matrix, reaching a sensitivity for cholesterol of $0.13 \mu \mathrm{A} \mu \mathrm{M}^{-1}$. The addition of MWCNT to the electrode prior to the deposition of the electron transfer, P450scc enzyme, once the enzyme had been immobilized, would increase sensitivity more than 17 times with respect to bare electrodes, or 2.4 times with respect to the electrode containing gold nanoparticles. This catalytic effect is shown in Figure 1. Although the sensitivity to cholesterol was of the same order as using the gold nanoparticles, the linearity in the response improved significantly in the range of 10 to $80 \mu \mathrm{M}$.

Li et al. [86] also proved the electron transfer improvement with MWCNT in an electrode containing ferrocyanide, POD, ChOx and cholesterol estearase. They performed clinical trials in blood of 31 patients with the biosensor showing fairly good correlation between this method and the results obtained by a clinical blood analyzer.

2.3. Hybridization Sensors. The detection of specific sequences of DNA is a booming field due to its applications for diagnosis of pathogenic and genetic diseases, forensic analysis, drug screening and environmental testing. Different

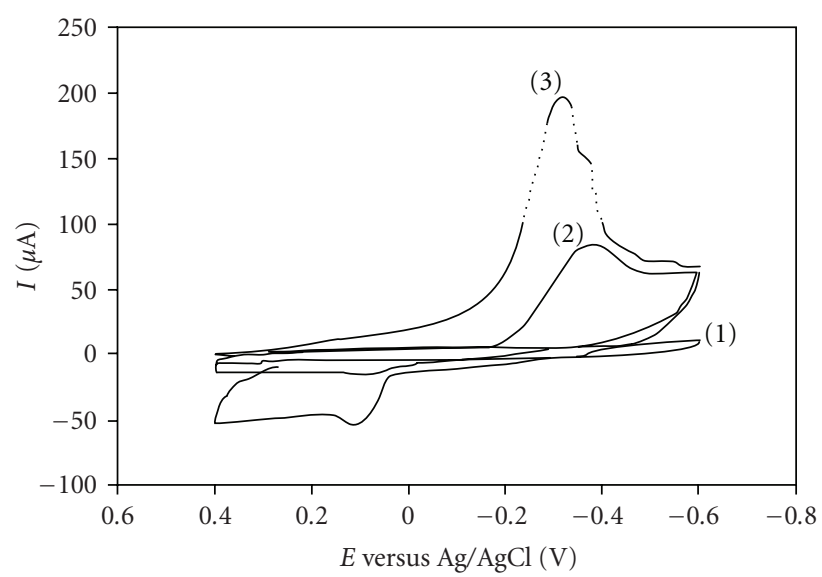

Figure 1: Cyclic voltammograms of screen-printed bare rhodiumgraphite electrode for cholesterol detection (1), on electrodes modified with Au nanoparticles and P450scc (2), or with multiwalled carbon nanotubes and P450scc (3). Experiments were performed under aerobic conditions, $100 \mathrm{mM}$ phosphate buffer, $50 \mathrm{mM} \mathrm{KCl}, \mathrm{pH} \mathrm{7.4}$, and the scan rate was $50 \mathrm{mV} \mathrm{s}^{-1}$. With permission from [83].

strategies can be used for the detection of DNA in sensors, among them the most useful tools are the intrinsic electroactivity of nucleic acids [87], the use of DNA duplex intercalators [88], the labelling with enzymes [89], or the addition of electroactive markers [90].

Metallic nanoparticles (NPs) have emerged as appealing electroactive markers in electrochemical sensors, especially in stripping voltammetry. This technique is cheap, simple and fast in comparison with optical methods in which commercial DNA chips are based. Another advantage of the use of nanoparticles in DNA hybridization sensors is their multiplexing capability, being able to recognize different molecules in the same sample due to the distinct voltammetric waves produced by different electrochemical tracers [91]. Additionally, their life cycle is much longer than other markers, making their use even more attractive.

Although most of the work of application of metallic nanoparticles for DNA recognition events is performed in other types of electrodes (e.g., gold disks [92], glassy carbon electrodes [93], graphite-epoxy composite electrodes [94], pencil graphite electrode [95]) some examples have emerged regarding the use of SPE in combination with elements from nanotechnology and will be studied in the following paragraphs.

Wang et al. [96] developed a hybridization assay employing a combination of electrodes: a probe-modified gold surface and an SPE. The method was based on the electrostatic collection of silver cations along the DNA duplex, the reductive formation of silver nanoclusters along the DNA backbone, the dissolution of the silver aggregate with a nitric acid solution and the stripping voltammetry detection of the dissolved silver with the SPE. A scheme of the working protocol is shown in Figure 2.

DNA segments related with the BRCA breast-cancer gene were detected to concentrations as low as $200 \mathrm{ng} / \mathrm{mL}$ 


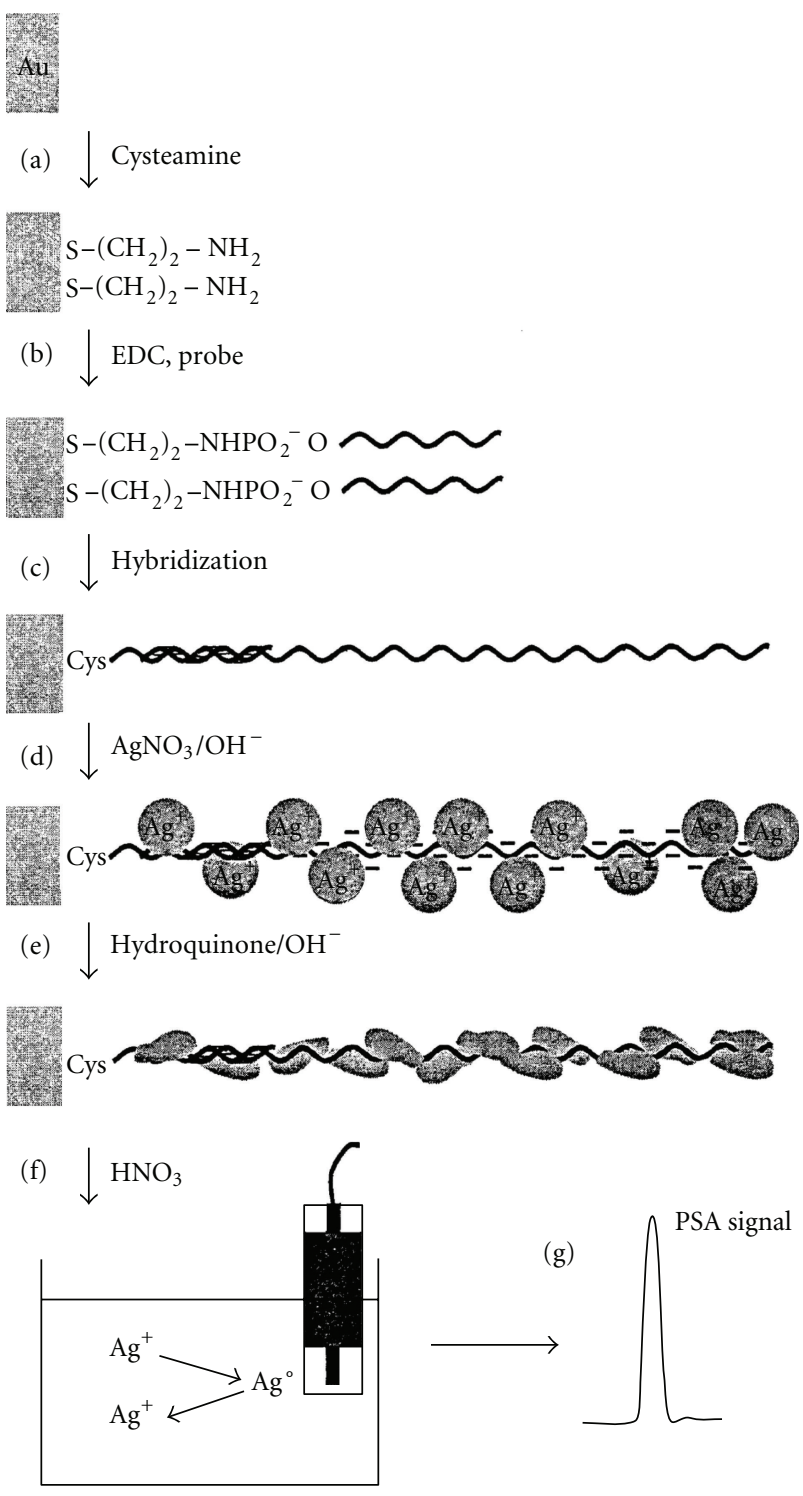

FIgURE 2: Immobilization and analytical protocol for DNA hybridization detection. (a) Formation of self-assembled cysteamine monolayer, (b) immobilization of ssDNA probe, (c) hybridization of complementary target, (d) "loading" of the silver ion to DNA, (e) hydroquinone-catalyzed reduction of silver ions to form silver aggregates on the DNA backbone, (f) dissolution of the silver aggregates in nitric acid (50\%) and transfer to the detection cell, (g) stripping potentiometric detection with SPE. From [96] with the permission of Elsevier.

with an original strategy developed also by Wang et al. [97]. It was based on the use of magnetic particles as tools to perform DNA hybridization. The assay involved the hybridization of a target oligonucleotide to probe-coated magnetic beads, followed by binding of the streptavidincoated gold nanoparticles to the capture target and catalytic silver precipitation on the gold-particle tags. The DNAlinked particle assembly was then magnetically collected onto a screen printing electrode surface with a permanent magnet positioned bellow. This way a direct contact between the silver tag with the surface was managed and the solidstate electrochemical transduction was enabled. This silver aggregate did not form in the presence of only noncomplimentary DNA. The described method did not require acidic solution or metal deposition of the silver, so the time needed for the assay was reduced. This technique of combined magnetism and metal detection is now used frequently for DNA hybridization detection not only for screen-printed sensors but also with other electrodic supports.

Suprun et al. [98] recently published the design of an SPE with gold nanoparticles (AuNPs) included in its surface as an electrochemical sensing platform of interactions from the protein thrombine and the thrombin binding aptamer. The nanostructrured DNA aptasensor had the aptamer immobilized to the AuNP by avidin-biotin linkages. Detection of a binding between aptamer (APT) and thrombin was performed by introducing the aliquots of the targets and binding-buffer onto the electrodes. The difference between cathodic peak areas in the system SPE/ AuNP/ APT/ thrombin and in the SPE/ AuNP/ APT/ buffer was measured in a stripping voltammetry with $E_{\mathrm{ox}}=+1.2 \mathrm{~V}$, and a calibration curve was built for different thrombin concentrations. The thrombin detection limit was $10^{-9} \mathrm{M}$.

The same detection limit $\left(10^{-9} \mathrm{M}\right)$ was also found for a thrombin biosensor designed by Kerman and Tamiya [99]. They developed an aptamer-based sandwich assay where the primary aptamer was immobilized on the surface of the SPE and the secondary aptamer on the AuNP. The electrochemical reduction current response of the Au nanoparticles was monitored to quantify detection of thrombin.

Gold nanoparticles and stripping voltammetry were employed by Authier et al. [95] for the quantitative detection of amplified human cytomegalovirus (HCMV) DNA. In this case it was only the oligonucleotide probe which was marked with gold nanoparticles. The detection was permitted after the release of the gold metal atoms anchored on the hybrids by oxidative metal dissolution, given rise to a response with anodic stripping voltammetry at a sandwich type screen printed microband electrode. With this technique it was possible to detect $5 \mathrm{pM}$-amplified HCMV DNA fragment.

2.4. Drugs Determination. New applications for SPE are emerging for determination of drugs in the pharmaceutical and biomedical fields. Recently Shih et al. [100] determined codeine, an effective analgesic and antitussive agent in pharmaceutical preparations. They developed a nontronite clay-modified screen-printed carbon electrode that detected codeine in urine by square wave stripping voltammetry. The codeine quantification was achieved by measuring the oxidation peak after background subtraction in voltammograms run between 0.6 and $1.3 \mathrm{~V}$ at a square wave frequency of $15 \mathrm{~Hz}$ and amplitude of $45 \mathrm{mV}$. Under these conditions they found linearity for codeine detection in the range of 2.5 to $45 \mu \mathrm{M}$.

Burgoa Calvo et al. [101] developed a silver nanoparticlemodified carbon SPE to detect lamotrigine (LTG), a new generation antiepileptic drug for treatment of patients with refractory partial seizures or without secondary generalization. They determined LTG by differential pulse adsorptive 
stripping voltammetry with a detection limit of $3.7 \times 10^{-7} \mathrm{M}$. The SPE used was modified with silver nanoparticles that had been electrodeposited from $\mathrm{AgNO}_{3}$ in an acidic BrittonRobison solution by accumulating potential during a time under stirring. They studied different parameters of silver deposition to optimize the intensity of the reduction peak at $-1.06 \mathrm{~V}$ needed for the LTG quantification. Good agreement was found between the level stated by the manufacturer of commercial capsules and the one measured by the biosensor.

Enzymatic amperometric sensors with gold nanoparticles have just been developed [102] for the determination of Phenobarbital, a first generation of anticonvulsant drug widely used to treat epilepsy. Different electrode preparation methods were evaluated to immobilize covalently the enzyme, cytochrome P450 2B4. The best results were obtained in gold SPE modified with electrodeposited gold nanoparticles and with the cytochrome attached covalently by Mercapto Propionic Acid/ Nhidroxysuccinimide with $\mathrm{N}$-(3-dimethylamoinopropyl)- $\mathrm{N}^{\prime}$ ethylcarbodiimide hydrochloride, or in carbon SPE functionalised with diazonium salt. The former covalent attachment in gold SPE without nanoparticles did not give any response to Phenobarbital. The same research group detected another antiepileptic drug, leveticeratum, by carbon screenprinted electrodes [103] but in this case without modification by nanoparticles, using peroxidase immobilization by pyrrole electropolimerization.

Martinez et al. [104] designed an MWCNT-modified SPE for Methimazole (MT) determination in pharmaceutical formulations. MT is used as a drug to manage hyperthyroidism associated with Grave's disease, but it has side effects as possible decrease of white blood cells in the blood. The designed sensor consisted of a rotating disk together with an MWCNT-modified graphite SPE (the working electrode was drop casted with a dispersion of the MWCNT in a mixture of methanol, water and Nafion). The rotating disk contained tyrosinase immobilized in its surface, which catalyzed the oxidation of catechol (C) to o-benzoquinone (BQ). The back electrochemical reduction of BQ was detected on MWCNTmodified graphite SPE at $-150 \mathrm{mV}$ versus $\mathrm{Ag} / \mathrm{AgCl} / \mathrm{NaCl}$ $3 \mathrm{M}$. Thus, when MT was added to the solution, this thiolcontaining compound participate in Michael type addition reactions with $\mathrm{BQ}$ to form the corresponding thioquinone derivatives, decreasing the reduction current obtained proportionally to the increase of its concentration. This method made possible the determination of MT for concentrations from 0.074 to $63.5 \mu \mathrm{M}$ with a reproducibility of $3.5 \%$.

2.5. Ethanol Quantification. Quantification of ethanol is useful not only in clinical diagnostic analyses but also in fermentation and distillation processes. The amperometric biosensing response of ethanol can be based in two approaches: using alcohol oxidase (AOX) or alcohol dehydrogenase $(\mathrm{ADH})$ as catalytic enzyme [52]. In the first case AOX is employed to catalyze the formation of aldehydes and $\mathrm{H}_{2} \mathrm{O}_{2}$ by oxidizing low molecular alcohols with $\mathrm{O}_{2}$. The electrochemical response would be given by the mediated oxidation of $\mathrm{H}_{2} \mathrm{O}_{2}$, as in other biosensoric

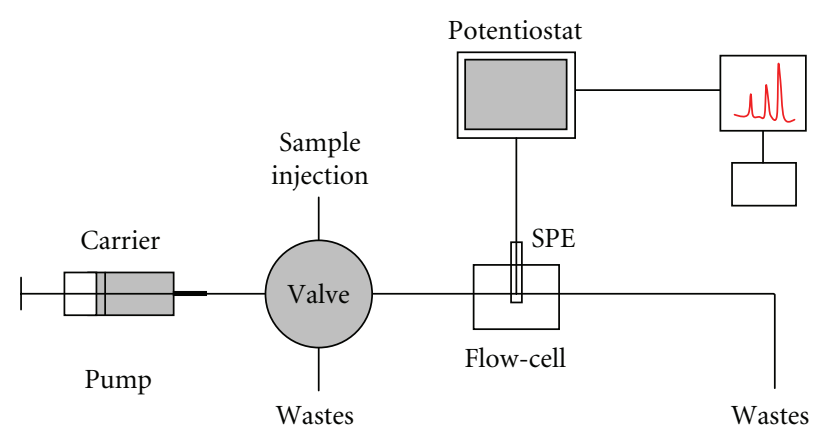

(a)

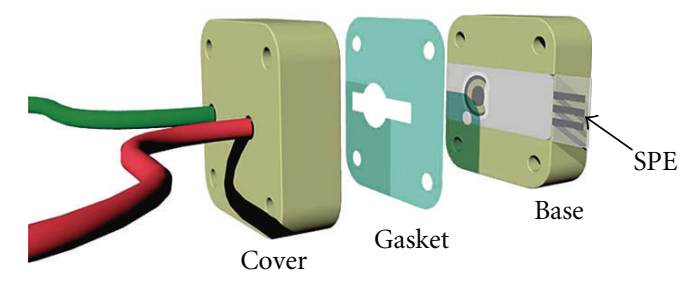

(b)

Figure 3: (a) Schematic diagram of the flow-injection sensing system. (b) 3D image of the electrochemical flow-cell containing the modified SPE. With permission from [106].

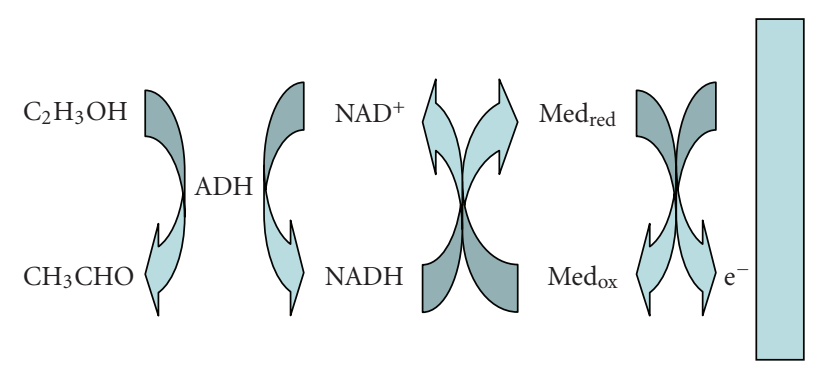

Scheme 1: Detection of ethanol at the biosensor surface catalyzed by alcohol dehydrogenase $(\mathrm{ADH})$.

detections (glucose, cholesterol). This is the case of the screen-printed sensor designed to determine ethanol in beer, built by Boujtita et al. [105], using cobalt phthalocyanine as mediator.

The second approach uses the action of the enzyme ADH catalyzing the oxidation of ethanol or other primary alcohols (excepting methanol) following Scheme 1. This mechanism was used by Liao et al. [107] to built an ethanol biosensor with ferricyanide-magnetite nanoparticles as mediator. They used the two-step immobilization method that $\mathrm{Lu}$ and Chen [69] had previously employed for glucose sensing. The method involved drop coating the carbon working electrode with a mix of $\mathrm{Fe}_{3} \mathrm{O}_{4}$ and ferrricyanide, drying this layer at high temperature, and posterior addition of the enzyme in buffer (in this case $\mathrm{ADH}$ from baker's yeast $(\mathrm{YADH})$ and $\mathrm{NAD}^{+}$). The $\mathrm{NAD}^{+}-\mathrm{YADH} /$ Ferri-Fe $\mathrm{O}_{4}$ based biosensor worked at $200 \mathrm{mV}$ and showed excellent sensitivity for ethanol in buffer: $0.61 \mu \mathrm{A} \mathrm{mM}^{-1}$. 
The use of nickel nanowires with SPE for ethanol/glucose detection was previously revised in the Section 2.1. Additionally, multi-segmented nickel-gold-nickel nanowires were recently employed in the detection of ethanol [29]. The principle of use was similar to the procedure reported for glucose/ethanol [27], but in this case the electrodic support to control magnetically the orientation of the nanowires was not a screen printed electrode but a glassy carbon disk.

\section{SPE for Detection of Environmental Pollutants}

3.1. Pesticides. The use of organophosphorus and carbamate pesticides in agriculture has risen exponentially in the last decade causing public concern regarding the environment and food safety. For this reason, many examples of screenprinted electrodes have been proposed for detection of pesticides to substitute other techniques such as HPLC that require trained personnel and can be time consuming and tedious. Most of the screen-printed biosensors are enzymatic systems based on cholinesterase (ChE) inhibition, alone or in combination with choline oxidase (CHO), or noninhibition systems based on organophosporus hydrolase (OPH). However the applications of the later are quite limited since $\mathrm{OPH}$ is not a commercial enzyme. Few examples have also been reported using tyrosinase as biocomponent.

Andreescu and Marty [108] compiled in a good review the advances in cholinesterase biosensors, describing immobilization procedures, different designs and configurations including screen printing electrodes and practical applications. However, there is only one reference related to the use of nanomaterials on pesticide detection with SPE. The appearance of more work in this area will entitle us to complete that work.

Lin et al. [109] modified in 2003 the classical system of amperometric bienzymatic biosensor for pesticide detection that was used from the late 1980s (see Scheme 2) applying multiwalled carbon nanotubes covalently linked to the enzymes. The MWCNT were dispersed in DMF and dried over the carbon working area of the screenprinted electrode; they created carboxylic groups in their surface. Both enzymes were then immobilized by forming amide linkages with the MWCNT using 1-ethyl-3-(3-dimethylaminopropyl) carbodiimide (EDC) as coupling agent. Performing amperometric detections at $500 \mathrm{mV}$ parathion was detected in buffer, without the use of mediators obtaining a linear calibration curve from 50 to $200 \mu \mathrm{M}$ and a low detection limit of $0.05 \mu \mathrm{M}$.

Cai and $\mathrm{Du}[110]$ reported very recently the detection of Carbaryl using an MWCNT-based composite in screen-printed carbon electrodes. The nanotube containing composite was used to modify the other classic approach of pesticide detection: the monoenzymatic approach using cholinesterase to catalyze the hydrolysis of thiocholine (see Scheme 3). Since thiocholine is already electroactive, its oxidation is the reaction to be studied, without the need of a second enzyme. When pesticides are present they inhibit the catalysis of thiocholine formation and a decrease in the signal is observed. Classically, this approach is used with mediators in the system $(\mathrm{CoPh}, \mathrm{PB})$ and the amperometric study of thiocholine oxidation can be performed at a low oxidation potential such as $100 \mathrm{mV}$. However, Cai and Du, avoided the use of mediators with the use of the MWCN-crosslinked cellulose acetate composite, with the cholinesterase covalently bounded to it. This was possible due to the catalytical activity of the nanotubes toward the oxidation of the enzymatically produced thiocholine. The percentage of inhibition of the thiocholine oxidation signal for different concentrations of Carbaryl was obtained by quantifying the peak current at the $535 \mathrm{mV}$ oxidation peak that appeared in cyclic voltammetry before and after inhibition. The detection limit of this sensor for Carbaryl was $0.004 \mu \mathrm{g} / \mathrm{mL}$ concentration (equivalent to a $10 \%$ decrease in signal).

A carbon nanotube-modified screen-printed sensor combined with a flow-injection system has been built very recently [106] for the assessment of salivary cholinesterase enzyme activity as an exposure biomarker of pesticides. The modification of the carbon screen-printed electrode was performed by drop casting of an aqueous dispersion of MWCNT, leaving it to dry naturally over the working electrode. A diagram of the flow injection system with the incorporated SPE is shown in Figure 3. A quick and noninvasive approach was reached to determine pesticide exposure by measuring the activity of cholinesterase in rat saliva via the electrochemical monitoring of oxidation of thiocholine production (see Figure 3 ). In this case the enzyme is not immobilized in the SPE but present in the saliva.

3.2. Metals. Although essential metals play an integral role in the life processes of living organisms being catalysts in biochemical reactions or essential nutrients, some other metals have no biological role (such as silver, aluminium, cadmium, gold, lead and mercury). High concentrations of most metals, regardless of being essential or nonessential are toxic for living cells [111]. Thus, there is a growing demand for rapid, inexpensive and reliable sensors for measurement of metals not only in the environment but also in biomedical and industrial samples. In this sense, SPE can be of great use for metal detection since it has been proved that they give comparable results to those obtained by more expensive, laboratory-based techniques [112].

In the past five years, research has been developed on the use of the enzyme urease as biorecognition element in screen-printed biosensors for the detection of metal ions [113-115]. However, no records have been found for urease inhibition-based SPE containing metallic- or carbon-based nanomaterials.

On the other hand, there are many other examples of screen-printed sensors without including any enzyme or biorecognition element (i.e., sensors, not biosensors) for metallic ion detection (see Figure 4) and some of them have seen improvements by the incorporation of nanomaterials. This section will focus on them. In most of the cases they are based on voltammetric stripping analysis, a technique that traditionally was undertaken by $\mathrm{Hg}$ electrodes and 


$$
\text { (CH }
$$

Scheme 2: First generation bi-enzymatic ChE/ChO amperometric biosensor [108]. With permission from Elsevier.

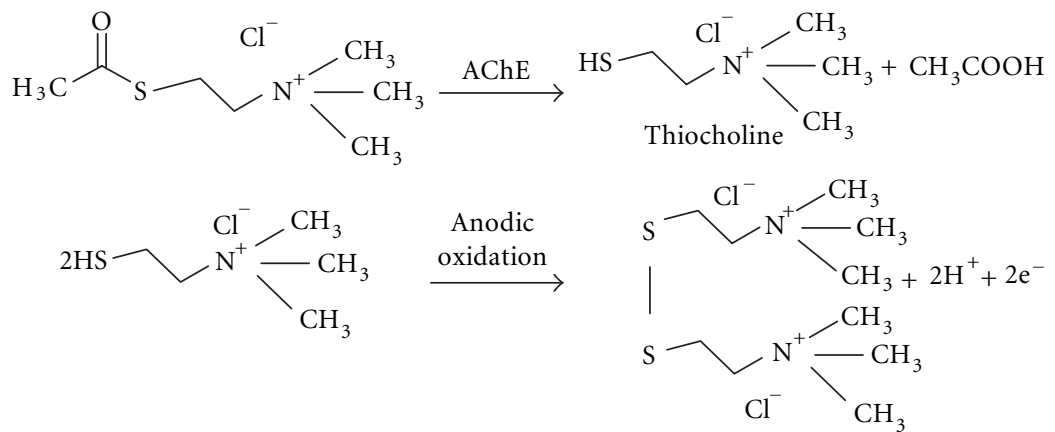

Scheme 3: Approach used in monoenzymatic electrodes. In presence of pesticides the catalytic formation of thiocholine is partially inhibited and less electrochemical response is obtained for the oxidation of thiocholine.

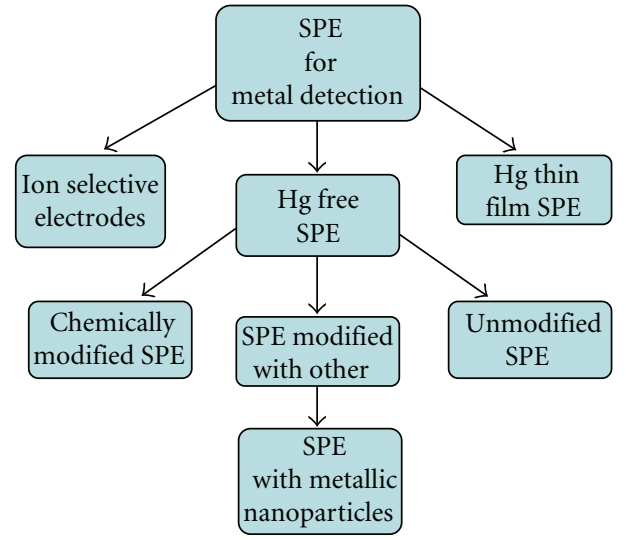

FIGURE 4: Different approaches for detection of metals with screenprinted electrodes.

that is one of the most sensitive alternatives for metal ion determination.

Domínguez-Renedo et al. [37] have recently published the detection of chromium (VI), a strong carcinogenic and toxic species, by means of an SPE modified by electrochemical deposition of metallic nanoparticles. Both gold and silver nanoparticle-modified electrodes were tested toward $\mathrm{Cr}$ (VI) by differential pulse voltammetry. For the electrode preparation, the silver deposition was similar to the procedure described by this group for lamotrigine detection [101] (see Section 2.4). For the electrodes that were modified with gold nanoparticles, a solution of $0.5 \mathrm{M} \mathrm{H}_{2} \mathrm{SO}_{4}$ containing $0.1 \mathrm{mM}$ of $\mathrm{AuClO}_{4}$ was used for the electrochemical deposition of gold at the graphite working electrode, at a potential of $0.18 \mathrm{~V}$ during 200 seconds. While the best results in terms of sensibility $\left(4 \times 10^{-7} \mathrm{M}\right)$ and reproducibility $(\%$ RSD $=3.2)$ were obtained by the gold nanomodified sensors, the silver-modified ones offered no interference in presence of any tested metallic ion (gold-modified sensors showed interference with $\mathrm{Cu}(\mathrm{II})$ in concentrations higher than $10^{-5} \mathrm{M}$ ).

The same preparation techniques for silver and gold nanoparticles in SPE were employed a year earlier to detect $\mathrm{Sb}$ (III) $[116,117]$. In that case, the detection was performed using anodic stripping voltammetry. A sensitivity of $6.8 \times$ $10^{-10} \mathrm{M}$ was reached in the case of silver nanoparticles, while $9.4 \times 10^{-10} \mathrm{M}$ was measured in the case of gold nanoparticles. Common interferants in anodic stripping voltammetry (such as bismuth) did not affect the electrochemical response of these sensors.

Nanogold-modified SPEs were also employed to detect As(III) [118]. In this case the working electrode was previously treated with Triton X-100 solution. The goldnanoparticles were obtained dissolving poly (L-lactide) in THF containing $\mathrm{HAuCl}_{4}$ with posterior addition of $\mathrm{NaBH}_{4}$. The poly-L-lactide-established nanoparticles were then drop coated on the pretreated working electrode. Differential pulse anodic stripping voltammetry was also used here obtaining a linear calibration curve up to $4 \mathrm{ppb}$ of As(III) with a detection limit $(\mathrm{S} / \mathrm{N}=3)$ of $0.09 \mathrm{ppb}$. Using the same types of electrodes, an indirect method to detect traces of 
hydrogen sulphide was developed [119] by measuring the inhibited oxidation current of As(III). The detection limit for hydrogen sulphide was $0.04 \mu \mathrm{M}$.

3.3. Other Pollutants. Nitrites can contaminate water, foodstuff and environmental matrices by conversion into carcinogenic nitrosamines. Its quantitative determination is therefore of increasing interest. There is a large number of electrochemical sensors developed with this purpose [120127], some of them including nanomaterials [122-130] but only one example [131] has been encountered using SPE and nanotechnology. The later work consisted of the immobilization of hemoglobin $(\mathrm{Hb})$ into SPE containing colloidal gold nanoparticles incorporated into carbon ink. An unmediated sensor was thus created with sensitivity for nitrites of $0.1 \mu \mathrm{M}$. The colloidal gold nanoparticles decreased the background current, improved the conductivity, amplified the electrochemical signal, helped to retain the bioactivity and accelerated the electron transfer rate.

Hydrazine and its derivatives are potential reducing agents of environmental and toxicological significance. The application of SPE for the detection of this compound was performed already in 1995 for Wang and Pamidi [132]. They printed only the working electrode as a strip containing cobalt phtalocianine or modified with mixed valent ruthenium and detected hydrazine spiked samples with concentrations of $10^{-5} \mathrm{M}$ by amperometric and voltammetric measurements. No biomolecule was required. More recent work [133] includes the application of copper-palladium alloy nanoparticle plated screen-printed electrodes in a flow injection analysis system, reaching a linear detection range of $2-100 \mu \mathrm{M}$ and a detection limit of $270 \mathrm{nM}$. The SPE, prepared under successive electrochemical deposition of $\mathrm{Cu}$ and $\mathrm{Pd}$, showed and enhanced hydrazine electrocatalytic response at low detection potentials in neutral media.

\section{Conclusions and Perspectives}

This review has summarized recent applications of nanotechnology in thick film electrochemical sensors. Apart from a revision of the state of the art for this printing technique, the article has gathered different types of screen printing sensing devices by application topic. In every topic a brief introduction has been given to explain the mechanism of detection, followed by examples of nanotechnology applications, emphasizing on the preparation of the (bio)sensor and its response. The reported examples have shown situations where metallic nanoparticles and carbon nanotubes have been valuable for screen-printed sensors in different ways.

(i) To substitute the use of other mediators, as it was demonstrated with MWCNT or iridium nanoparticles for $\mathrm{H}_{2} \mathrm{O}_{2}$ detection, substituting prusian blue in glucose sensors, or riboflavin in cholesterol sensors. The same was demonstrated with MWCNT in pesticide detection.

(ii) As labels or electroactive markers for stripping voltammetry. Metallic nanoparticles were used to improve detection in SPE genosensors, to test drugs, or to detect metallic pollutants in SPE sensors. (iii) To retain the bioactivity of enzymes once they have been immobilized in the sensor, as it was the case of gold nanoparticles with hemoglobine in nitrite sensors.

(iv) To eliminate interferences, as the Au and Ag nanoparticles in Sb sensors, where the interference of bismuth is not observed.

(v) To improve the sensitivity of the devices. The increase in the surface area of the working electrode generally leads to more sensitive responses.

As summary, the coupling of electrochemical screenprinted sensors with nanoscale materials is being used as a tool for improved sensitivity, longer stability of the bioelement in biosensors and new detection possibilities. The application of nanomaterials in this type of electrochemical devices is still in progress and literature continues to grow and broaden. Although the use of nanotechnology in screenprinted sensors may not be the only key needed to solve some problems faced occasionally by these sensors (e.g., selectivity in some applications), it is certainly a step forward, and the implemented improvements are multiplying the future possibilities of these disposable sensor devices.

\section{References}

[1] P. L. Baumbach, "Electrochemical sensor construction,” UK patent no. 2073891, 1981.

[2] M. Lambrechts, J. Suls, and W. Sansen, "A thick film glucose sensor," in Proceedings of the 9th Annual Conference of the IEEE Engineering in Medicine and Biology Society (EMBS '87), pp. 789-799, Boston, Mass, USA, November 1987.

[3] D. R. Matthews, R. R. Holman, E. Bown, et al., "Pen-sized digital 30-second blood glucose meter," The Lancet, vol. 1, no. 8536, pp. 778-779, 1987.

[4] C. C. Liu, "Apparatus and method for sensing species, substances and substrates using oxidase," US Patent 4655880 , 1987.

[5] X.-E. Zhang, "Screen printing methods for biosensor production," in Biosensors, J. Cooper and T. Cass, Eds., pp. 4158, Oxford University Press, Oxford, UK, 2nd edition, 2004.

[6] S. Andreescu, L. Barthelmebs, and J.-L. Marty, "Immobilization of acetylcholinesterase on screen-printed electrodes: comparative study between three immobilization methods and applications to the detection of organophosphorus insecticides," Analytica Chimica Acta, vol. 464, no. 2, pp. 171180, 2002.

[7] S. Sánchez, M. Pumera, E. Cabruja, and E. Fàbregas, "Carbon nanotube/polysulfone composite screen-printed electrochemical enzyme biosensors," Analyst, vol. 132, no. 2, pp. 142-147, 2007.

[8] F. Arduini, F. Ricci, C. S. Tuta, D. Moscone, A. Amine, and G. Palleschi, "Detection of carbamic and organophosphorous pesticides in water samples using a cholinesterase biosensor based on Prussian Blue-modified screen-printed electrode," Analytica Chimica Acta, vol. 580, no. 2, pp. 155-162, 2006.

[9] H. Sántha, R. Dobay, and G. Harsányi, "Amperometric uric acid biosensors fabricated of various types of uricase enzymes," IEEE Sensors Journal, vol. 3, no. 3, pp. 282-287, 2003. 
[10] G. Cui, S. J. Kim, S. H. Choi, H. Nam, G. S. Cha, and K.J. Paeng, "A disposable amperometric sensor screen printed on a nitrocellulose strip: a glucose biosensor employing lead oxide as an interference-removing agent," Analytical Chemistry, vol. 72, no. 8, pp. 1925-1929, 2000.

[11] C. A. Galán-Vidal, J. Muñoz, C. Domínguez, and S. Alegret, "Glucose biosensor strip in a three electrode configuration based on composite and biocomposite materials applied by planar thick film technology," Sensors and Actuators B, vol. 52, no. 3, pp. 257-263, 1998.

[12] F. J. Rawson, W. M. Purcell, J. Xu, et al., "A microband lactate biosensor fabricated using a water-based screenprinted carbon ink," Talanta, vol. 77, no. 3, pp. 1149-1154, 2009.

[13] R. M. Pemberton, R. Pittson, N. Biddle, and J. P. Hart, "Fabrication of microband glucose biosensors using a screenprinting water-based carbon ink and their application in serum analysis," Biosensors \& Bioelectronics, vol. 24, no. 5, pp. 1246-1252, 2009.

[14] E. Crouch, D. C. Cowell, S. Hoskins, R. W. Pittson, and J. P. Hart, "Amperometric, screen-printed, glucose biosensor for analysis of human plasma samples using a biocomposite water-based carbon ink incorporating glucose oxidase," Analytical Biochemistry, vol. 347, no. 1, pp. 17-23, 2005.

[15] E. Crouch, D. C. Cowell, S. Hoskins, R. W. Pittson, and J. P. Hart, "A novel, disposable, screen-printed amperometric biosensor for glucose in serum fabricated using a water-based carbon ink," Biosensors \& Bioelectronics, vol. 21, no. 5, pp. 712-718, 2005.

[16] M. Tudorache and C. Bala, "Biosensors based on screenprinting technology, and their applications in environmental and food analysis," Analytical and Bioanalytical Chemistry, vol. 388, no. 3, pp. 565-578, 2007.

[17] M. Albareda-Sirvent, A. Merkoçi, and S. Alegret, "Configurations used in the design of screen-printed enzymatic biosensors. A review," Sensors and Actuators B, vol. 69, no. 1, pp. 153-163, 2000.

[18] R. Solná, S. Sapelnikova, P. Skládal, et al., "Multienzyme electrochemical array sensor for determination of phenols and pesticides," Talanta, vol. 65, no. 2, pp. 349-357, 2005.

[19] R. Solná, E. Dock, A. Christenson, et al., "Amperometric screen-printed biosensor arrays with co-immobilised oxidoreductases and cholinesterases," Analytica Chimica Acta, vol. 528, no. 1, pp. 9-19, 2005.

[20] A. Crew, J. P. Hart, R. Wedge, J. L. Marty, and D. Fournier, "A screen-printed, amperometric, biosensor array for the detection of organophosphate pesticides based on inhibition of wild type, and mutant acetylcholinesterases, from Drosophila melanogaster," Analytical Letters, vol. 37, no. 8, pp. 16011610, 2004.

[21] S. Laschi, I. Palchetti, G. Marrazza, and M. Mascini, "Development of disposable low density screen-printed electrode arrays for simultaneous electrochemical measurements of the hybridisation reaction," Journal of Electroanalytical Chemistry, vol. 593, no. 1-2, pp. 211-218, 2006.

[22] I. Willner, R. Baron, and B. Willner, "Integrated nanoparticle-biomolecule systems for biosensing and bioelectronics," Biosensors \& Bioelectronics, vol. 22, no. 9-10, pp. 1841-1852, 2007.

[23] V. A. Pedrosa, X. Luo, J. Burdick, and J. Wang, "“Nanofingers" based on binary gold-polypyrrole nanowires," Small, vol. 4, no. 6, pp. 738-741, 2008.
[24] T. J. Morrow, M. Li, J. Kim, T. S. Mayer, and C. D. Keating, "Programmed assembly of DNA-coated nanowire devices," Science, vol. 323, no. 5912, p. 352, 2009.

[25] B. He, T. J. Morrow, and C. D. Keating, "Nanowire sensors for multiplexed detection of biomolecules," Current Opinion in Chemical Biology, vol. 12, no. 5, pp. 522-528, 2008.

[26] E. Piccin, R. Laocharoensuk, J. Burdick, E. Carrilho, and J. Wang, "Adaptive nanowires for switchable microchip devices," Analytical Chemistry, vol. 79, no. 12, pp. 4720-4723, 2007.

[27] J. Wang, M. Scampicchio, R. Laocharoensuk, F. Valentini, O. González-García, and J. Burdick, "Magnetic tuning of the electrochemical reactivity through controlled surface orientation of catalytic nanowires," Journal of the American Chemical Society, vol. 128, no. 14, pp. 4562-4563, 2006.

[28] R. Laocharoensuk, A. Bulbarello, S. B. Hocevar, S. Mannino, B. Ogorevc, and J. Wang, "On-demand protection of electrochemical sensors based on adaptive nanowires," Journal of the American Chemical Society, vol. 129, no. 25, pp. 7774-7775, 2007.

[29] R. Laocharoensuk, A. Bulbarello, S. Mannino, and J. Wang, "Adaptive nanowire-nanotube bioelectronic system for on-demand bioelectrocatalytic transformations," Chemical Communications, no. 32, pp. 3362-3364, 2007.

[30] U. Yogeswaran and S.-M. Chen, "A review on the electrochemical sensors and biosensors composed of nanowires as sensing material," Sensors, vol. 8, no. 1, pp. 290-313, 2008.

[31] Ó. A. Loaiza, R. Laocharoensuk, J. Burdick, et al., "Adaptive orientation of multifunctional nanowires for magnetic control of bioelectrocatalytic processes," Angewandte Chemie International Edition, vol. 46, no. 9, pp. 1508-1511, 2007.

[32] J. Shen, L. Dudik, and C.-C. Liu, "An iridium nanoparticles dispersed carbon based thick film electrochemical biosensor and its application for a single use, disposable glucose biosensor," Sensors and Actuators B, vol. 125, no. 1, pp. 106113, 2007.

[33] P. Fanjul-Bolado, P. Queipo, P. J. Lamas-Ardisana, and A. Costa-García, "Manufacture and evaluation of carbon nanotube modified screen-printed electrodes as electrochemical tools," Talanta, vol. 74, no. 3, pp. 427-433, 2007.

[34] J. Wang, M. Musameh, and Y. Lin, "Solubilization of carbon nanotubes by Nafion toward the preparation of amperometric biosensors," Journal of the American Chemical Society, vol. 125, no. 9, pp. 2408-2409, 2003.

[35] S. Laschi, E. Bulukin, I. Palchetti, C. Cristea, and M. Mascini, "Disposable electrodes modified with multi-wall carbon nanotubes for biosensor applications," IRBM, vol. 29, no. 23, pp. 202-207, 2008.

[36] G. A. Rivas, M. D. Rubianes, M. C. Rodríguez, et al., "Carbon nanotubes for electrochemical biosensing," Talanta, vol. 74, no. 3, pp. 291-307, 2007.

[37] O. Domínguez-Renedo, L. Ruiz-Espelt, N. García-Astorgano, and M. J. Arcos-Martínez, "Electrochemical determination of chromium(VI) using metallic nanoparticle-modified carbon screen-printed electrodes," Talanta, vol. 76, no. 4, pp. 854858, 2008.

[38] J. Wang, "Nanomaterial-based electrochemical biosensors," Analyst, vol. 130, no. 4, pp. 421-426, 2005.

[39] G. B. Sergeev, "Nanoparticles in science and technology," in Nanochemistry, pp. 175-208, Elsevier, Amsterdam, The Netherlands, 2006.

[40] C. M. Welch and R. G. Compton, "The use of nanoparticles in electroanalysis: a review," Analytical and Bioanalytical Chemistry, vol. 384, no. 3, pp. 601-619, 2006. 
[41] P. Alivisatos, "The use of nanocrystals in biological detection," Nature Biotechnology, vol. 22, no. 1, pp. 47-52, 2004.

[42] E. Bakker, "Electrochemical sensors," Analytical Chemistry, vol. 76, no. 12, pp. 3285-3298, 2004.

[43] A. Ambrosi, A. Merkoçi, and A. de la Escosura-Muñiz, "Electrochemical analysis with nanoparticle-based biosystems," TrAC Trends in Analytical Chemistry, vol. 27, no. 7, pp. 568584, 2008.

[44] A. Erdem, "Nanomaterial-based electrochemical DNA sensing strategies," Talanta, vol. 74, no. 3, pp. 318-325, 2007.

[45] J. Wang, "Carbon-nanotube based electrochemical biosensors: a review," Electroanalysis, vol. 17, no. 1, pp. 7-14, 2005.

[46] M. Pumera, S. Sánchez, I. Ichinose, and J. Tang, "Electrochemical nanobiosensors," Sensors and Actuators B, vol. 123, no. 2, pp. 1195-1205, 2007.

[47] X.-J. Huang and Y.-K. Choi, "Chemical sensors based on nanostructured materials," Sensors and Actuators B, vol. 122, no. 2, pp. 659-671, 2007.

[48] I. Willner, R. Baron, and B. Willner, "Integrated nanoparticle-biomolecule systems for biosensing and bioelectronics," Biosensors \& Bioelectronics, vol. 22, no. 9-10, pp. 1841-1852, 2007.

[49] Y. Yun, Z. Dong, V. Shanov, et al., "Nanotube electrodes and biosensors," Nano Today, vol. 2, no. 6, pp. 30-37, 2007.

[50] V. Vamvakaki and N. A. Chaniotakis, "Carbon nanostructures as transducers in biosensors," Sensors and Actuators B, vol. 126, no. 1, pp. 193-197, 2007.

[51] X.-E. Zhang, "Screen-printing methods for biosensor production," in Biosensors, J. Cooper and T. Cass, Eds., Practical Approach Series, pp. 41-58, Oxford University Press, Oxford, UK, 2004.

[52] O. Domínguez-Renedo, M. A. Alonso-Lomillo, and M. J. Arcos-Martínez, "Recent developments in the field of screenprinted electrodes and their related applications," Talanta, vol. 73, no. 2, pp. 202-219, 2007.

[53] J. P. Hart, A. Crew, E. Crouch, K. C. Honeychurch, and R. M. Pemberton, "Screen-printed electrochemical (bio)sensors in biomedical, environmental and industrial applications," in Electrochemical Sensor Analysis, S. Alegret and A. Merkoçi, Eds., vol. 49, pp. 497-557, Elsevier, Amsterdam, The Netherlands, 2007.

[54] S. Laschi and M. Mascini, "Planar electrochemical sensors for biomedical applications," Medical Engineering \& Physics, vol. 28, no. 10, pp. 934-943, 2006.

[55] J. P. Hart, A. Crew, E. Crouch, K. C. Honeychurch, and R. M. Pemberton, "Some recent designs and developments of screen-printed carbon electrochemical sensors/biosensors for biomedical, environmental, and industrial analyses," Analytical Letters, vol. 37, no. 5, pp. 789-830, 2004.

[56] A. Avramescu, S. Andreescu, T. Noguer, C. Bala, D. Andreescu, and J.-L. Marty, "Biosensors designed for environmental and food quality control based on screen-printed graphite electrodes with different configurations," Analytical and Bioanalytical Chemistry, vol. 374, no. 1, pp. 25-32, 2002.

[57] V. B. Nascimento and L. Angnes, "Eletrodos fabricados por "silk-screen"', Química Nova, vol. 21, no. 5, pp. 614-629, 1998.

[58] J. D. Newman and A. P. F. Turner, "Home blood glucose biosensors: a commercial perspective," Biosensors \& Bioelectronics, vol. 20, no. 12, pp. 2435-2453, 2005.

[59] H. J. Hecht, H. M. Kalisz, J. Hendle, R. D. Schmid, and D. Schomburg, "Crystal structure of glucose oxidase from Aspergillus niger refined at $2.3 \AA$ reslution," Journal of Molecular Biology, vol. 229, no. 1, pp. 153-172, 1993.
[60] I. L. de Mattos, L. Gorton, and T. Ruzgas, "Sensor and biosensor based on Prussian Blue modified gold and platinum screen printed electrodes," Biosensors \& Bioelectronics, vol. 18, no. 2-3, pp. 193-200, 2002.

[61] K. Derwinska, K. Miecznikowski, R. Koncki, P. J. Kulesza, S. Glab, and M. A. Malik, "Application of Prussian Blue based composite film with functionalized organic polymer to construction of enzymatic glucose biosensor," Electroanalysis, vol. 15, no. 23-24, pp. 1843-1849, 2003.

[62] W. Zhao, J.-J. Xu, C.-G. Shi, and H.-Y. Chen, "Multilayer membranes via layer-by-layer deposition of organic polymer protected Prussian Blue nanoparticles and glucose oxidase for glucose biosensing," Langmuir, vol. 21, no. 21, pp. 96309634, 2005

[63] T. Li, Z. Yao, and L. Ding, "Development of an amperometric biosensor based on glucose oxidase immobilized through silica sol-gel film onto Prussian Blue modified electrode," Sensors and Actuators B, vol. 101, no. 1-2, pp. 155-160, 2004.

[64] A. Lupu, D. Compagnone, and G. Palleschi, "Screen-printed enzyme electrodes for the detection of marker analytes during winemaking," Analytica Chimica Acta, vol. 513, no. 1, pp. 67-72, 2004.

[65] S. Zuo, Y. Teng, H. Yuan, and M. Lan, "Development of a novel silver nanoparticles-enhanced screen-printed amperometric glucose biosensor," Analytical Letters, vol. 41, no. 7, pp. 1158-1172, 2008.

[66] P. A. Fiorito, V. R. Gonçales, E. A. Ponzio, and S. I. Córdoba de Torresi, "Synthesis, characterization and immobilization of Prussian Blue nanoparticles. A potential tool for biosensing devices," Chemical Communications, no. 3, pp. 366-368, 2005.

[67] W.-J. Guan, Y. Li, Y.-Q. Chen, X.-B. Zhang, and G.-Q. Hu, "Glucose biosensor based on multi-wall carbon nanotubes and screen printed carbon electrodes," Biosensors \& Bioelectronics, vol. 21, no. 3, pp. 508-512, 2005.

[68] M. D. Rubianes and G. A. Rivas, "Carbon nanotubes paste electrode," Electrochemical Communications, vol. 5, no. 8, pp. 689-694, 2003.

[69] B.-W. Lu and W.-C. Chen, "A disposable glucose biosensor based on drop-coating of screen-printed carbon electrodes with magnetic nanoparticles," Journal of Magnetism and Magnetic Materials, vol. 304, no. 1, pp. e400-e402, 2006.

[70] L. M. Rossi, A. D. Quach, and Z. Rosenzweig, "Glucose oxidase-magnetite nanoparticle bioconjugate for glucose sensing," Analytical and Bioanalytical Chemistry, vol. 380, no. 4, pp. 606-613, 2004.

[71] Z. Gao, F. Xie, M. Shariff, M. Arshad, and J. Y. Ying, "A disposable glucose biosensor based on diffusional mediator dispersed in nanoparticulate membrane on screen-printed carbon electrode," Sensors and Actuators B, vol. 111-112, pp. 339-346, 2005.

[72] Z. Gao, G. Xu, Y.-R. J. Ying, M. Shariff, M. Arshad, and F. Xie, "Biosensor," WO/2005/040404, 2005.

[73] N. Bragagnolo and D. B. Rodriguez-Amaya, "Simultaneous determination of total lipid, cholesterol and fatty acids in meat and backfat of suckling and adult pigs," Food Chemistry, vol. 79, no. 2, pp. 255-260, 2002.

[74] B.-S. Hwang, J.-T. Wang, and Y.-M. Choong, "A simplified method for the quantification of total cholesterol in lipids using gas chromatography," Journal of Food Composition and Analysis, vol. 16, no. 2, pp. 169-178, 2003.

[75] M. A. T. Gilmartin and J. P. Hart, "Fabrication and characterization of a screen-printed, disposable, amperometric cholesterol biosensor," Analyst, vol. 119, no. 11, pp. 23312336, 1994. 
[76] L. Charpentier and N. El Murr, "Amperometric determination of cholesterol in serum with use of a renewable surface peroxidase electrode," Analytica Chimica Acta, vol. 318, no. 1, pp. 89-93, 1995.

[77] T. Nakaminami, S. Kuwabata, and H. Yoneyama, "Electrochemical oxidation of cholesterol catalyzed by cholesterol oxidase with use of an artificial electron mediator," Analytical Chemistry, vol. 69, no. 13, pp. 2367-2372, 1997.

[78] F. Ricci and G. Palleschi, "Sensor and biosensor preparation, optimisation and applications of Prussian Blue modified electrodes," Biosensors \& Bioelectronics, vol. 21, no. 3, pp. 389-407, 2005.

[79] S. Cosnier, A. Senillou, M. Grätzel, et al., "Glucose biosensor based on enzyme entrapment within polypyrrole films electrodeposited on mesoporous titanium dioxide," Journal of Electroanalytical Chemistry, vol. 469, no. 2, pp. 176-181, 1999.

[80] J. Wang, X. Zhang, and M. Prakash, "Glucose microsensors based on carbon paste enzyme electrodes modified with cupric hexacyanoferrate," Analytica Chimica Acta, vol. 395, no. 1-2, pp. 11-16, 1999.

[81] S. K. Arya, M. Datta, and B. D. Malhotra, "Recent advances in cholesterol biosensor," Biosensors \& Bioelectronics, vol. 23, no. 7, pp. 1083-1100, 2008.

[82] V. V. Shumyantseva, S. Carrara, V. Bavastrello, et al., "Direct electron transfer between cytochrome P450scc and gold nanoparticles on screen-printed rhodium-graphite electrodes," Biosensors \& Bioelectronics, vol. 21, no. 1, pp. 217222, 2005.

[83] S. Carrara, V. V. Shumyantseva, A. I. Archakov, and B. Samorì, "Screen-printed electrodes based on carbon nanotubes and cytochrome P450scc for highly sensitive cholesterol biosensors," Biosensors \& Bioelectronics, vol. 24, no. 1, pp. 148-150, 2008.

[84] N. Bistolas, U. Wollenberger, C. Jung, and F. W. Scheller, "Cytochrome P450 biosensors-a review," Biosensors \& Bioelectronics, vol. 20, no. 12, pp. 2408-2423, 2005.

[85] V. Shumyantseva, G. Deluca, T. Bulko, et al., "Cholesterol amperometric biosensor based on cytochrome P450scc," Biosensors \& Bioelectronics, vol. 19, no. 9, pp. 971-976, 2004.

[86] G. Li, J. M. Liao, G. Q. Hu, N. Z. Ma, and P. J. Wu, "Study of carbon nanotube modified biosensor for monitoring total cholesterol in blood," Biosensors \& Bioelectronics, vol. 20, no. 10, pp. 2140-2144, 2005.

[87] F. Jelen, B. Yosypchuk, A. Kourilová, L. Novotný, and E. Paleček, "Label-free determination of picogram quantities of DNA by stripping voltammetry with solid copper amalgam or mercury electrodes in the presence of copper," Analytical Chemistry, vol. 74, no. 18, pp. 4788-4793, 2002.

[88] P. Kara, K. Kerman, D. Ozkan, et al., "Electrochemical genosensor for the detection of interaction between methylene blue and DNA," Electrochemistry Communications, vol. 4, no. 9, pp. 705-709, 2002.

[89] D. J. Caruana and A. Heller, "Enzyme-amplified amperometric detection of hybridization and of a single base pair mutation in an 18-base oligonucleotide on a 7- $\mu \mathrm{m}$-diameter microelectrode," Journal of the American Chemical Society, vol. 121, no. 4, pp. 769-774, 1999.

[90] J. Wang, R. Polsky, A. Merkoçi, and K. L. Turner, “"Electroactive beads" for ultrasensitive DNA detection," Langmuir, vol. 19, no. 4, pp. 989-991, 2003.

[91] A. Merkoçi, "Electrochemical biosensing with nanoparticles," FEBS Journal, vol. 274, no. 2, pp. 310-316, 2007.
[92] D. Du, J. Ding, Y. Tao, H. Li, and X. Chen, "CdTe nanocrystalbased electrochemical biosensor for the recognition of neutravidin by anodic stripping voltammetry at electrodeposited bismuth film," Biosensors \& Bioelectronics, vol. 24, no. 4, pp. 869-874, 2008.

[93] S. Niu, M. Zhao, L. Hu, and S. Zhang, "Carbon nanotubeenhanced DNA biosensor for DNA hybridization detection using rutin-Mn as electrochemical indicator," Sensors and Actuators B, vol. 135, no. 1, pp. 200-205, 2008.

[94] M.T. Castañeda, A. Merkoçi, M. Pumera, and S. Alegret, "Electrochemical genosensors for biomedical applications based on gold nanoparticles," Biosensors \& Bioelectronics, vol. 22, no. 9-10, pp. 1961-1967, 2007.

[95] L. Authier, C. Grossiord, P. Brossier, and B. Limoges, "Gold nanoparticle-based quantitative electrochemical detection of amplified human cytomegalovirus DNA using disposable microband electrodes," Analytical Chemistry, vol. 73, no. 18, pp. 4450-4456, 2001.

[96] J. Wang, O. Rincón, R. Polsky, and E. Dominguez, "Electrochemical detection of DNA hybridization based on DNAtemplated assembly of silver cluster," Electrochemistry Communications, vol. 5, no. 1, pp. 83-86, 2003.

[97] J. Wang, D. Xu, and R. Polsky, "Magnetically-induced solid-state electrochemical detection of DNA hybridization," Journal of the American Chemical Society, vol. 124, no. 16, pp. 4208-4209, 2002.

[98] E. Suprun, V. Shumyantseva, T. Bulko, et al., "Aunanoparticles as an electrochemical sensing platform for aptamer-thrombin interaction," Biosensors \& Bioelectronics, vol. 24, no. 4, pp. 831-836, 2008.

[99] K. Kerman and E. Tamiya, "Aptamer-functionalized Au nanoparticles for the electrochemical detection of thrombin," Journal of Biomedical Nanotechnology, vol. 4, no. 2, pp. 159164, 2008.

[100] W.-C. Shih, M.-C. Yang, and M. S. Lin, "Development of disposable lipid biosensor for the determination of total cholesterol," Biosensors \& Bioelectronics, vol. 24, no. 6, pp. 1679-1684, 2009.

[101] M. E. Burgoa Calvo, O. Domínguez-Renedo, and M. J. ArcosMartínez, "Determination of lamotrigine by adsorptive stripping voltammetry using silver nanoparticle-modified carbon screen-printed electrodes," Talanta, vol. 74, no. 1, pp. 59-64, 2007.

[102] M. A. Alonso-Lomillo, C. Yardimci, O. Domínguez-Renedo, and M. J. Arcos-Martínez, "CYP450 2B4 covalently attached to carbon and gold screen printed electrodes by diazonium salt and thiols monolayers," Analytica Chimica Acta, vol. 633, no. 1, pp. 51-56, 2009.

[103] M. A. Alonso-Lomillo, O. Domínguez-Renedo, P. Matos, and M. J. Arcos-Martínez, "Electrochemical determination of levetiracetam by screen-printed based biosensors," Bioelectrochemistry, vol. 74, no. 2, pp. 306-309, 2009.

[104] N. A. Martinez, G. A. Messina, F. A. Bertolino, E. Salinas, and J. Raba, "Screen-printed enzymatic biosensor modified with carbon nanotube for the methimazole determination in pharmaceuticals formulations," Sensors and Actuators B, vol. 133, no. 1, pp. 256-262, 2008.

[105] M. Boujtita, J. P. Hart, and R. Pittson, "Development of a disposable ethanol biosensor based on a chemically modified screen-printed electrode coated with alcohol oxidase for the analysis of beer," Biosensors \& Bioelectronics, vol. 15, no. 5-6, pp. 257-263, 2000. 
[106] J. Wang, C. Timchalk, and Y. Lin, "Carbon nanotube-based electrochemical sensor for assay of salivary cholinesterase enzyme activity: an exposure biomarker of organophosphate pesticides and nerve agents," Environmental Science and Technology, vol. 42, no. 7, pp. 2688-2693, 2008.

[107] M.-H. Liao, J.-C. Guo, and W.-C. Chen, "A disposable amperometric ethanol biosensor based on screen-printed carbon electrodes mediated with ferricyanide-magnetic nanoparticle mixture," Journal of Magnetism and Magnetic Materials, vol. 304, no. 1, pp. e421-e423, 2006.

[108] S. Andreescu and J.-L. Marty, "Twenty years research in cholinesterase biosensors: from basic research to practical applications," Biomolecular Engineering, vol. 23, no. 1, pp. 1$15,2006$.

[109] Y. Lin, F. Lu, and J. Wang, "Disposable carbon nanotube modified screen-printed biosensor for amperometric detection of organophosphorus pesticides and nerve agents," Electroanalysis, vol. 16, no. 1-2, pp. 145-149, 2004.

[110] J. Cai and D. Du, "A disposable sensor based on immobilization of acetylcholinesterase to multiwall carbon nanotube modified screen-printed electrode for determination of carbaryl," Journal of Applied Electrochemistry, vol. 38, no. 9, pp. 1217-1222, 2008.

[111] I. Bontidean, A. Mortari, S. Leth, et al., "Biosensors for detection of mercury in contaminated soils," Environmental Pollution, vol. 131, no. 2, pp. 255-262, 2004.

[112] K. C. Honeychurch and J. P. Hart, "Screen-printed electrochemical sensors for monitoring metal pollutants," TrAC Trends in Analytical Chemistry, vol. 22, no. 7-8, pp. 456-469, 2003.

[113] D. Ogończyk, L. Tymecki, I. Wyżkiewicz, R. Koncki, and S. Głąb, "Screen-printed disposable urease-based biosensors for inhibitive detection of heavy metal ions," Sensors and Actuators B, vol. 106, no. 1, pp. 450-454, 2005.

[114] B. B. Rodriguez, J. A. Bolbot, and I. E. Tothill, "Development of urease and glutamic dehydrogenase amperometric assay for heavy metals screening in polluted samples," Biosensors \& Bioelectronics, vol. 19, no. 10, pp. 1157-1167, 2004.

[115] B. B. Rodriguez, J. A. Bolbot, and I. E. Tothill, "Ureaseglutamic dehydrogenase biosensor for screening heavy metals in water and soil samples," Analytical and Bioanalytical Chemistry, vol. 380, no. 2, pp. 284-292, 2004.

[116] O. Domínguez-Renedo and M. J. Arcos-Martínez, "A novel method for the anodic stripping voltammetry determination of $\mathrm{Sb}$ (III) using silver nanoparticle-modified screen-printed electrodes," Electrochemistry Communications, vol. 9, no. 4, pp. 820-826, 2007.

[117] O. Domínguez-Renedo and M. J. Arcos-Martínez, "Anodic stripping voltammetry of antimony using gold nanoparticlemodified carbon screen-printed electrodes," Analytica Chimica Acta, vol. 589, no. 2, pp. 255-260, 2007.

[118] Y.-S. Song, G. Muthuraman, Y.-Z. Chen, C.-C. Lin, and J.-M. Zen, "Screen printed carbon electrode modified with poly(Llactide) stabilized gold nanoparticles for sensitive as(III) detection," Electroanalysis, vol. 18, no. 18, pp. 1763-1770, 2006.

[119] Y.-S. Song, G. Muthuraman, and J.-M. Zen, “Trace analysis of hydrogen sulfide by monitoring As(III) at a poly(Llactide) stabilized gold nanoparticles modified electrode," Electrochemistry Communications, vol. 8, no. 8, pp. 13691374, 2006.

[120] W. J. R. Santos, P. R. Lima, A. A. Tanaka, S. M. C. N. Tanaka, and L. T. Kubota, "Determination of nitrite in food samples by anodic voltammetry using a modified electrode," Food Chemistry, vol. 113, no. 4, pp. 1206-1211, 2009.
[121] M. Sohail and S. B. Adeloju, "Electroimmobilization of nitrate reductase and nicotinamide adenine dinucleotide into polypyrrole films for potentiometric detection of nitrate," Sensors and Actuators B, vol. 133, no. 1, pp. 333-339, 2008.

[122] M. G. Almeida, C. M. Silveira, and J. J. G. Moura, "Biosensing nitrite using the system nitrite redutase/Nafion/methyl viologen—a voltammetric study," Biosensors \& Bioelectronics, vol. 22, no. 11, pp. 2485-2492, 2007.

[123] H. Chen, C. Mousty, L. Chen, and S. Cosnier, "A new approach for nitrite determination based on a HRP/catalase biosensor," Materials Science \& Engineering C, vol. 28, no. 56, pp. 726-730, 2008.

[124] H. Chen, C. Mousty, S. Cosnier, C. Silveira, J. J. G. Moura, and M. G. Almeida, "Highly sensitive nitrite biosensor based on the electrical wiring of nitrite reductase by [ZnCr-AQS] LDH," Electrochemistry Communications, vol. 9, no. 9, pp. 2240-2245, 2007.

[125] S. Cosnier, S. Da Silva, D. Shan, and K. Gorgy, "Electrochemical nitrate biosensor based on poly(pyrrole-viologen) film-nitrate reductase-clay composite," Bioelectrochemistry, vol. 74, no. 1, pp. 47-51, 2008.

[126] W. Dhaoui, M. Bouzitoun, H. Zarrouk, H. B. Ouada, and A. Pron, "Electrochemical sensor for nitrite determination based on thin films of sulfamic acid doped polyaniline deposited on $\mathrm{Si} / \mathrm{SiO}_{2}$ structures in electrolyte/insulator/semiconductor (E.I.S.) configuration," Synthetic Metals, vol. 158, no. 17-18, pp. 722-726, 2008.

[127] Z. Zhang, S. Xia, D. Leonard, et al., "A novel nitrite biosensor based on conductometric electrode modified with cytochrome $c$ nitrite reductase composite membrane," Biosensors \& Bioelectronics, vol. 24, no. 6, pp. 1574-1579, 2009.

[128] Z. Dai, H. Bai, M. Hong, Y. Zhu, J. Bao, and J. Shen, "A novel nitrite biosensor based on the direct electron transfer of hemoglobin immobilized on CdS hollow nanospheres," Biosensors \& Bioelectronics, vol. 23, no. 12, pp. 1869-1873, 2008.

[129] X. Huang, Y. Li, Y. Chen, and L. Wang, "Electrochemical determination of nitrite and iodate by use of gold nanoparticles/poly(3-methylthiophene) composites coated glassy carbon electrode," Sensors and Actuators B, vol. 134, no. 2, pp. 780-786, 2008.

[130] A. Salimi, R. Hallaj, H. Mamkhezri, and S. M. T. Hosaini, "Electrochemical properties and electrocatalytic activity of FAD immobilized onto cobalt oxide nanoparticles: application to nitrite detection," Journal of Electroanalytical Chemistry, vol. 619-620, no. 1-2, pp. 31-38, 2008.

[131] X. Xu, S. Liu, B. Li, and H. Ju, "Disposable nitrite sensor based on hemoglobin-colloidal gold nanoparticle modified screen-printed electrode," Analytical Letters, vol. 36, no. 11, pp. 2427-2442, 2003.

[132] J. Wang and P. V. A. Pamidi, "Disposable screen-printed electrodes for monitoring hydrazines," Talanta, vol. 42, no. 3, pp. 463-467, 1995.

[133] C.-C. Yang, A. S. Kumar, M.-C. Kuo, S.-H. Chien, and J.-M. Zen, "Copper-palladium alloy nanoparticle plated electrodes for the electrocatalytic determination of hydrazine," Analytica Chimica Acta, vol. 554, no. 1-2, pp. 66-73, 2005. 

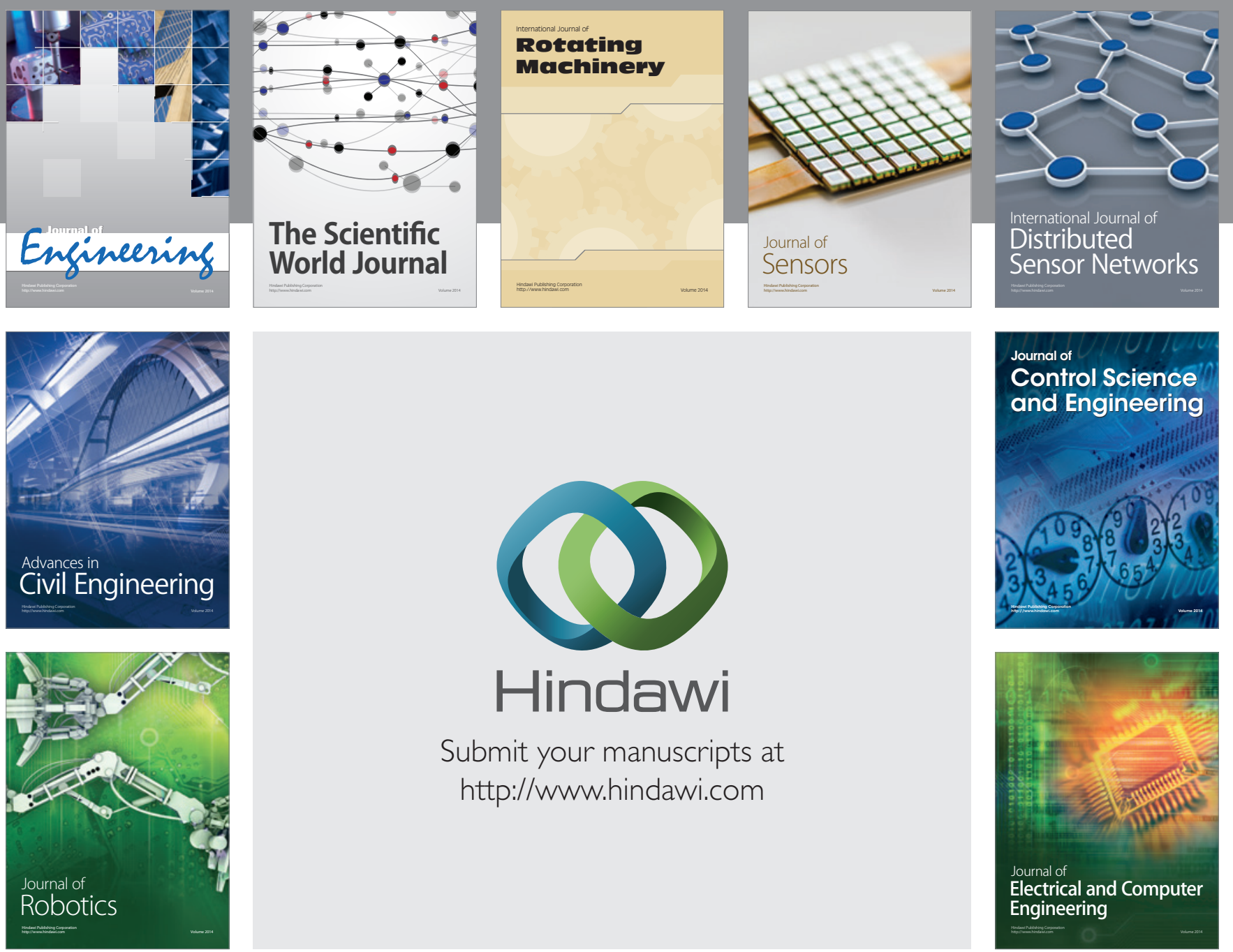

Submit your manuscripts at

http://www.hindawi.com
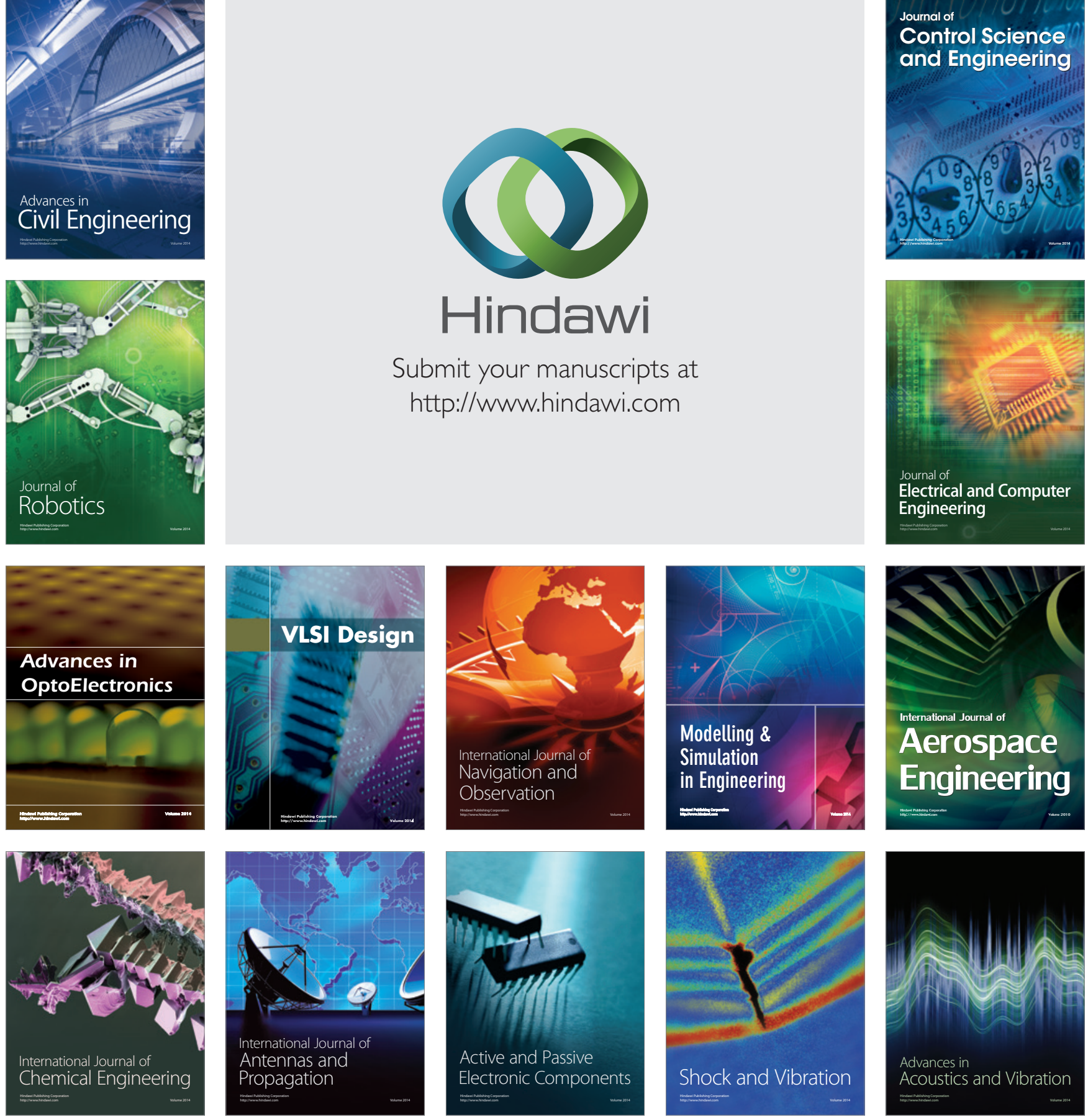